\title{
The Risk Factors of Intensive Care Unit Admittance during First Attack of Acute Pancreatitis
}

\author{
Jonas Dale ${ }^{1,2}$, Thomas Omdal ${ }^{1,2}$, Stein Atle Lie ${ }^{3,4}$, Knut Iversen $^{5}$, Hans Flaaten ${ }^{5,6}$, \\ Kjell Kore Ovrebo ${ }^{2,5}$ \\ ${ }^{1}$ Medical Student Research Program, Faculty of Medicine and Dentistry, University of Bergen, Bergen, Norway \\ ${ }^{2}$ Department of Surgery, Haukeland University Hospital, Bergen, Norway \\ ${ }^{3}$ Department of Surgical Sciences, Haukeland University Hospital, Bergen, Norway \\ ${ }^{4}$ Uni Health, Bergen, Norway \\ ${ }^{5}$ Department of Surgery, Haraldsplass Deaconess Hospital, Bergen, Norway \\ ${ }^{6}$ Department of Anesthesia and Intensive Care, Haukeland University Hospital, Bergen, Norway \\ Email: dale.jonas@gmail.com
}

Received October 3, 2012; revised November 5, 2012; accepted November 15, 2012

\begin{abstract}
Background: A proportion of patients with acute pancreatitis develop severe organ dysfunction requiring admittance in an intensive care unit. Patient characteristics associated with ICU admittance were evaluated in this consecutive series of patients. Methods: The clinical course of patients with first attack of acute pancreatitis in urban Norway between 01.01.1996 and 31.12.2006 was reviewed. Patient characteristics, comorbidity, pre hospital delay and likely aetiology of acute pancreatitis were analysed as risk factors for ICU admittance. Results: This study includes 565 patients, 299 women and 266 men ( $p=0.089)$, with a median age of 60 years (range: 17 - 98). $50(9 \%)$ of the patients were admitted to the ICU. Men were more at risk than women for ICU admittance (OR 2.34; 95\% CI: 1.27 - 4.32). Patients with alcohol associated pancreatitis (OR 5.94; 95\%, CI: 2.61 - 13.53), miscellaneous aetiologies (OR: 2.81, 95\% CI: 1.02 - 7.73) and non-assessed aetiology (OR 2.71, 95\%, CI: 1.26 - 5.82) were more at risk of ICU admittance than patients with bile stones associated pancreatitis. Pre hospital delay increased the risk of ICU admittance amongst patients with alcohol associated pancreatitis (OR 4.23; 95\%, CI: 1.11 - 16.18). Two comorbid conditions conveyed increased risk (OR 8.78; 95\%, CI: 1.87 - 41.22). The case fatality rate was $24 \%$ in the ICU and $1.6 \%$ in the ward (OR 20.01, 95\% CI: 7.71 51.93). Conclusions: Aetiology of acute pancreatitis, especially alcohol, pre-hospital delay and male gender are associated with increased of risk of ICU admittance and increased fatality rate during first attack of AP.
\end{abstract}

Keywords: Pancreatitis; Intensive Care; Multiple Organ Failure

\section{Introduction}

The incidence rates for acute pancreatitis range from 5 to 80 cases pr 100,000 inhabitants per year [1,2]. The incidence rates of acute pancreatitis is increasing in Norway and varies between 14.6/100.000 - 30/100.000 per year $[3,4]$.

The courses of acute pancreatitis range from a mild self-limiting condition to severe fulminate disease with multi organ failure and death. Mild cases of acute pancreatitis resolve quickly with minimal care, whereas patients with severe acute pancreatitis often induce considerable strain on intensive care resources [5]. Approximately $20 \%$ of acute pancreatitis cases are severe, and account for more than $90 \%$ of pancreatitis associated deaths $[6,7]$.

Several scoring systems have been developed in order to investigate possible venues for identification of pa- tients at risk of developing severe acute pancreatitis. Clinical prognostic scores, biochemical markers and Computed Tomography Scores (CTS) are widely used [8-13]. Amongst these, the APACHE II score has been promising, with a positive predictive value as high as $69 \%$ for predicting severity of disease [14]. Ranson and Glasgow scores, although simpler to use in a clinical setting, do not achieve satisfactory sensitivity, specificity or predictive values [15]. Individual factors such as obesity, alcohol, smoking, specific organ failure and high age have also been associated with an increased risk of a severe acute pancreatitis [16-18].

Organ dysfunction and ICU admittance occurs in approximately $38 \%$ - $52 \%$ of patients with severe acute pancreatitis [5,19], and represents a worst case scenario associated with the most demanding treatment and the highest morbidity and mortality rates $(21.0 \%-53.6 \%)$ amongst patients with acute pancreatitis [5,20-22]. Ex- 
penses of ICU patients due to highly demanding continuous care, special equipment and therapeutic intervenetions exceed costs of patients treated in the wards by wide margins [5].

Thus, early recognition and treatment of patients at risk of multiple organ failure and a need of ICU admission with organ support is probably the most important differentiation amongst patients with acute pancreatitis.

This study was conducted in order to identify pancreatitis unrelated risk factors for ICU admittance. The risk factors should both precede in time the clinical condition leading to ICU admittance and be unrelated to progression or consequences of acute pancreatitis.

We hypothesised that patient factors such as age, comorbidity, likely aetiology of acute pancreatitis as well as patients delay prior to their first episode of acute pancreatitis might predict a course of acute pancreatitis leading to ICU admittance.

\section{Methods}

Patients hospitalized for acute pancreatitis in the urban area of Bergen, Norway between 01.01.1996 - 31.12.2006 were investigated retrospectively. Haukeland University Hospital (A Tertiary university teaching hospital with a stratified intensive care unit) and the Haraldsplass Deaconess Hospital (primary hospital without an intensive care unit) are the two only hospitals in this region. The hospitals report patients according to the International Classification of Diseases (ICD), ninth and tenth revision (ICD-9/10) to the joint computer database Patient Information Management System (PIMS). The computer database was searched for patients discharged with acute pancreatitis by code 577.0 (ICD-9) or K85 (ICD-10) as primary or secondary diagnosis. The patient records were reviewed and the diagnoses re-evaluated. Patient characteristics, clinical, biochemical and radio- logic data, and the clinical course were retrieved.

A diagnosis of acute pancreatitis was accepted when the patient records confirmed a positive clinical presentation for acute pancreatitis(characteristic pain) accompanyed by findings of s-Amylase values three times the upper normal level on admission [23], or a positive CT-scan with or without contrast. Only patients who had their first episode of acute pancreatitis within the specified timeframe, were included in the study. Patients were excluded from the study if they were suffering from recurrent episodes of acute pancreatitis, chronic pancreatitis or patients records from the early phase of disease were unavailable. 853 patients were identified with an episode of acute pancreatitis between 1996 and 2006. In 43 patients the medical record was inaccessible. 52 patients were transferred from outside our area to Haukeland University Hospital in order to receive specialized intensive care treatment or they were follow-ups after an episode of acute pancreatitis abroad. Complete records for the early phase of disease in this group of patients were unavailable.

The diagnosis acute pancreatitis could not be confirmed in 136 patients either by s-Amylase or a CT scan. 55 patients with previous episodes of acute pancreatitis were excluded. 565 (66\%) patients fulfilled the inclusion criteria and were hence included in the study. The recruitment of patients is shown in Figure 1.

Time from onset of symptoms to admission to hospital was calculated based on the admittance journal at the hospital. Prehospital symptom delay could be calculated in 509 patients (91\%). Patients admitted to the ICU were identified on the basis of their ICU journals. All patients transferred to the ICU had one or more organ failures that required reinforced treatment.

The aetiology of pancreatitis was identified from the patients' records and the association with bile stones oren-
Patients could not be evaluated $(\mathrm{n}=95)(11 \%)$ - Missing records $(n=43)$

- Transferred from outside the region $(n=52)$
853 patients registered

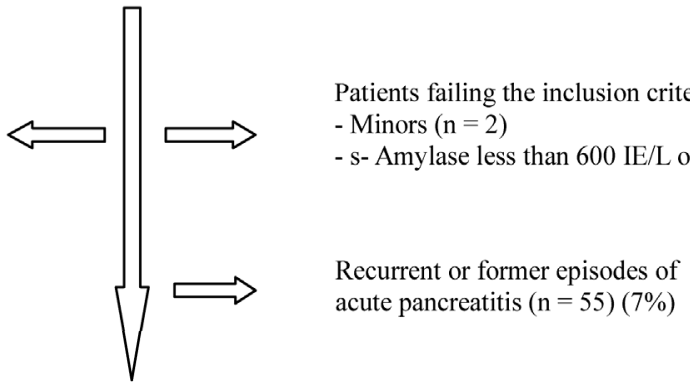

565 patients accepted $(66 \%)$

Figure 1. Chart illustrating patients registered with acute pancreatitis in the urban area of Bergen. Patients transferred to Haukeland University Hospital for intensive care treatment or specialized intervention adhere to populations (and epidemiology) of other regions and complete records for their early phase of disease were not available. Patients treated for acute pancreatitis outside this region and transferred for follow up appear in official registers, but data from the early phase of their disease could not be obtained or evaluated. 
doscopic retrograde cholangiopancreatography (ERCP) was verified by radiological findings (ultrasonography, computed tomography or ERCP). Alcohol was deemed as likely aetiology of acute pancreatitis when a history of binge drinking, alcohol abuse or regular consumption was noted and no other probable cause of acute pancreatitis could be identified. Pancreatic cancer or trauma, medication, disturbances in lipid metabolism, hypercalcsemic states, and post-infectious causes were found to be rare causes of acute pancreatitis, and therefore grouped together as miscellaneous causes of pancreatitis. The aetiology was classified as idiopathic when the above listed aetiologies had been considered without identification of a likely cause. The aetiology was categorized as not assessed when extensive review of the patient's records showed that no likely aetiology was verified and when all of the above-mentioned aetiological factors had not been considered.

Comorbidity was identified from the patient history. Coronary heart disease, lung disease requiring regular inhalations, diabetes mellitus, severe liver and kidney disease, and malignancies were identified. Less important comorbidities were noted, but not included in any analyses. Time from debut of symptoms until admittance to hospital was recorded as patient's prehospital delay.

The Regional Committee for Medical Research and Ethics in Western Norway approved the study.

\section{Statistics}

Analyses were performed using SPSS version 15.0. Data are presented as medians and range for continuous variables and as absolute frequencies for categorical variables. Categorical variables were analysed by Chi-square and Fishers exact tests. Mann-Whitney U-tests were used for continuous variables. Admission into ICU was analyzed using unadjusted and adjusted binary logistical regression models for variables believed to influence admission. A significance level of $\mathrm{p}<0.05$ was considered statistically significant.

\section{Results}

Of 565 patients with first episode of acute pancreatitis, 299 (53\%) were women and $266(47 \%)$ men $(p=0.089)$. Median age of patients was 60 years (range: 17 - 98). Patient characteristics and likely aetiology are summarized in Table 1. Comorbidity was identified in 209 (37\%) patients. Coronary heart disease, lung disease and former or concomitant malignant diseases dominated in this series of patients. Only lung diseases were statistically more prevalent amongst men (22.1\%) than amongst women (11.4\%) ( $\mathrm{p}=0.022)$. The records contained information on smoking habits in only 308 (55\%) of the cases. In these cases 60 (38\%) men and 46 women (30\%) admitted regular smoking $(\mathrm{p}=0.129)$. Inaccurate reporting of smoking habits precluded smoking from the analyses. Bile stone disease (50.1\%) and alcohol consumption (9.7\%) dominated the identified aetiologies. In $21.4 \%$ of cases, no likely cause of acute pancreatitis was identified. The likely aetiology of first episode acute pancreatitis varied across gender. Bile stone disease $(57.5 \%, \mathrm{p}<0.001)$ and post-ERCP acute pancreatitis $(5.4 \%, \mathrm{p}=0.005)$ were significantly more frequent as aetiology of acute pancreatitis amongst women than amongst men.

Alcohol (17.3\%, p < 0.001) and cases in which aetiology of acute pancreatitis had not been defined (25.6\%) were more common amongst men $(p=0.023)$. The time from onset of symptoms until admittance to the hospital varied and was similar amongst men and women with a median of 24 hours. Length of hospital and ICU stay varied considerably but there was no statistical difference between men and women (Table 1).

Table 1. Patients demographics, characteristics and possible aetiologies of acute pancreatitis.

\begin{tabular}{|c|c|c|c|c|}
\hline & Female & Male & Total & $\mathrm{p}$ \\
\hline Gender & 299 (52.9) & $266(47.1)$ & 565 & 0.089 \\
\hline $\begin{array}{l}\text { Age, Median } \\
\text { (Range) }\end{array}$ & $62(17-97)$ & $58(18-98)$ & $60(17-98)$ & 0.245 \\
\hline \multicolumn{5}{|l|}{ Comorbidity, n (\%) } \\
\hline - Coronary & 37 (35.2) & 31 (29.9) & $68(32.5)$ & 0.792 \\
\hline - Lung & $12(11.4)$ & $23(22.1)$ & 35 (16.7) & 0.022 \\
\hline - Malignancy & $20(19.1)$ & $12(11.5)$ & $32(15.3)$ & 0.263 \\
\hline - DM & $8(7.6)$ & $10(9.6)$ & $18(8.7)$ & 0.464 \\
\hline - Liver/Kidney & $4(3.8)$ & $7(6.7)$ & $11(5.3)$ & 0.266 \\
\hline $\begin{array}{l}\text { - Multiple } \\
\text { Comorbidity }\end{array}$ & 24 (22.9) & $21(20.2)$ & $45(21.5)$ & 0.953 \\
\hline \multicolumn{5}{|l|}{ Aetiology, n (\%) } \\
\hline - Gallstone & $172(57.5)$ & $111(41.7)$ & $283(50.1)$ & $<0.001$ \\
\hline - Alcohol & $9(3.0)$ & $46(17.3)$ & $55(9.7)$ & $<0.001$ \\
\hline $\begin{array}{l}\text { - Other/ } \\
\text { Miscellaneous }\end{array}$ & $27(9.0)$ & $20(7.5)$ & $47(8.3)$ & 0.516 \\
\hline -Idiopathic & $22(7.4)$ & $18(6.8)$ & $40(7.1)$ & 0.784 \\
\hline -ERCP & $16(5.4)$ & $3(1.1)$ & $19(3.4)$ & 0.005 \\
\hline -Not Asessed & $53(17.7)$ & $68(25.6)$ & $121(21.4)$ & 0.023 \\
\hline $\begin{array}{l}\text { Hours Delay, } \\
\text { Median (Range) }\end{array}$ & $24(1-360)$ & $24(1-408)$ & $24(1-408)$ & 0.735 \\
\hline $\begin{array}{l}\text { Days in } \\
\text { Hospital, } \\
\text { Median (Range) }\end{array}$ & $5(1-276)$ & $6(1-275)$ & $6(1-276)$ & 0.188 \\
\hline $\begin{array}{l}\text { Days in ICU, } \\
\text { Median (Range) }\end{array}$ & $4(1-28)$ & $5(1-82)$ & $5(1-82)$ & 0.319 \\
\hline
\end{tabular}

Comorbid diseases are listed for patients with single disease only. Time presented with median and range. p-values listed for comparison of gender. 


\section{ICU Admissions}

ICU admission was necessary in 50 (9\%) of first episode acute pancreatitis patients and 36 (72\%) of these patients stayed in the ICU for more than two days. ICU admission prolonged the median length of hospital stay from 5 (range: 1 - 276) days amongst acute pancreatitis patients cared for in the ward to a median of 22 (range: 1 - 269) days amongst ICU treated patients ( $\mathrm{p}<0.001)$. Moreover, ICU admittance was associated with a 24\% (12/50) mortality which is significantly increased from the $1.6 \%$ le- vel of mortality amongst acute pancreatitis patients in the surgical ward (OR: 20.01, 95\%, CI: 7.71 - 51.93, p < 0.001). The overall in-hospital mortality rate was $3.5 \%$.

The overall evaluation of patient factors suspected to predispose for ICU admittance during first episode of acute pancreatitis is summarized in Table 2. Men (66\%) were significantly more at risk than women (34\%) (OR: 2.34; 95\%, CI: 1.27 - 4.32, $\mathrm{p}=0.006$ ) to end up in the ICU. There was a tendency that symptomatic coronary heart disease increased the risk of ICU admittance $(p=0.075)$

Table 2. Patient factors and risk of ICU admittance during first episode of acute pancreatitis.

\begin{tabular}{|c|c|c|c|c|c|c|c|}
\hline \multirow{2}{*}{ Gender: } & \multicolumn{3}{|c|}{ Descriptive stats } & \multicolumn{4}{|c|}{ Unadjusted regression } \\
\hline & Uncomplicated n (\%) & ICU admission n (\%) & Total n (\%) & OR & \multicolumn{2}{|c|}{$95 \% \mathrm{CI}$} & $\mathrm{p}$ \\
\hline - Female & $282(94.3)$ & $17(5.7)$ & 299 (52.9) & 1 & & & \\
\hline - Male & $233(87.6)$ & $33(12.4)$ & $266(47.1)$ & 2.34 & 1.27 & 4.32 & 0.006 \\
\hline Age per 10 years & & & & 1.02 & 0.87 & 1.18 & 0.845 \\
\hline \multicolumn{8}{|l|}{ Comorbidity: } \\
\hline - None & $328(92.1)$ & $28(7.9)$ & $356(63.0)$ & 1 & & & \\
\hline - Coronary & $91(86.7)$ & $14(13.3)$ & 105 (18.5) & 1.81 & 0.93 & 3.49 & 0.076 \\
\hline - DM & $30(85.7)$ & 5 (14.3) & $35(6.1)$ & 1.79 & 0.66 & 4.85 & 0.248 \\
\hline - Liver/kidney & $17(85.0)$ & $3(15.0)$ & $20(3.5)$ & 1.87 & 0.52 & 6.61 & 0.332 \\
\hline - Malignancy & $41(91.1)$ & $4(8.9)$ & 45 (7.9) & 1.00 & 0.34 & 2.93 & 0.992 \\
\hline No of comorbidities: & & & & & & & 0.053 \\
\hline-0 & $328(92.1)$ & $28(7.9)$ & 356 (63.0) & 1 & & & \\
\hline-1 & 149 (90.9) & $15(9.1)$ & $164(29.0)$ & 1.17 & 0.61 & 2.27 & 0.622 \\
\hline-2 & 34 (89.5) & $4(10.5)$ & $38(6.7)$ & 1.37 & 0.45 & 4.16 & 0.570 \\
\hline$->3$ & $4(57.1)$ & 3 (42.9) & $7(1.2)$ & 8.78 & 1.87 & 41.22 & 0.006 \\
\hline \multicolumn{8}{|l|}{ Patient delay: } \\
\hline$->24 \mathrm{~h}$ & 193 (92.3) & $16(7.7)$ & 209 (41.1) & 0.67 & 0.35 & 1.25 & 0.211 \\
\hline Aetiology: & & & & & & & 0.001 \\
\hline - Bile stone & $269(95.1)$ & $14(4.9)$ & $283(50.1)$ & 1 & & & \\
\hline - Alcohol & $42(76.4)$ & $13(23.6)$ & $55(9.7)$ & 5.94 & 2.61 & 13.53 & 0.000 \\
\hline - Miscellaneous & $41(87.2)$ & $6(12.8)$ & $47(8.3)$ & 2.81 & 1.02 & 7.73 & 0.045 \\
\hline - Idiopathic & 39 (97.5) & $1(2.5)$ & $40(7.1)$ & 0.49 & 0.06 & 3.85 & 0.500 \\
\hline - ERCP & $18(94.7)$ & $1(5.3)$ & $19(3.4)$ & 1.06 & 0.13 & 8.58 & 0.951 \\
\hline - Not assessed & $106(87.6)$ & $15(12.4)$ & $121(21.4)$ & 2.71 & 1.26 & 5.82 & 0.010 \\
\hline
\end{tabular}

Many patients with a specified comorbidity had one or more additional comorbid conditions. Percentages shown for Uncomplicated and ICU admission as fractions of total in each row, whereas the percentage of total in each row are presented as fraction of total number of patients. 
whereas symptomatic lung disease, diabetes mellitus, liver and kidney diseases, or malignancy were statistically not separate risk factors for ICU admittance. However, the fraction of patients admitted to ICU without comorbidity (7.9\%), increased to $42.9 \%$ when 3 or more conditions were identified (OR 8.77, 95\% CI 1.80 - 41.22) $(p=0.006)$. Amongst the 283 patients with bile stone associated pancreatitis only 14 (4.9\%) patients needed ICU admission and patients with bile stones therefore served as reference in the analyses. Amongst patients with an alcohol associated acute pancreatitis, $23.6 \%$ of the patients were in need of intensive care (OR 5.94; 95\% CI 2.61 - 13.53, p < 0.001). The risk of an ICU admittance was also significantly increased amongst patients with miscellaneous aetiologies (12.8\%, OR 2.81, 95\% CI 1.02 - 7.73) and patients without a reported aetiology (12.4\%, OR 2.71, 95\% CI 1.26 - 5.82). Patients with pancreastitis following ERCP or idiopathic reasons were not at an increased risk of ICU admittance. Patients with a pre hospital delay of more than 24 hours represented statistically no increased risk of ICU admittance. However, with hours of delay as a continuous variable amongst patients with an alcohol associated acute pancreatitis, pre hospital delay was significantly associated with an increased risk of admittance to ICU (OR 1.01, 95\% CI 1.00 - 1.02, $\mathrm{p}=0.046)$. The risk for ICU admittance after 24 hours of delay was close to significant amongst patients with an alcohol aetiology ( $p=0.071$ ), but the risk was clearly significant when the delay exceeded three days (OR 4.23; 95\% CI 1.11 - 16.18, p = 0.035). Age, however, was not a risk factor for ICU admittance.

\subsection{Comorbidity}

Patients with different likely aetiologies for acute pancreatitis were checked across comorbidity and a significant association was identified (Table 3). The fraction of patients with one or several comorbidities was significantly higher amongst patients with non-assessed aetiology (47.1 \%, OR: 1.74, 95\%, CI: 1.13 - 2.68) than amongst patients with bile stone aetiology (33.9\%, ref), and a trend towards less comorbidity was noticed amongst patients with alcohol associated pancreatitis (21.8\%, OR: 0.54 , 95\%, CI: 0.27 - 1.08). Moreover, the average age of patients with alcohol associated acute pancreatitis was significantly lower than that of patients with bile stone, not assessed and miscellaneous aetiology (Table 4). Identical results were obtained by non-parametric tests.

\subsection{Gender Stratification}

Men and women were separately analysed due to the effect of gender on risk of ICU admission. A majority of women (62.4\%) were hospitalized within 24 hours of
Table 3. Etiology of first episode acute pancreatitis amongst patients with or without comorbidity.

\begin{tabular}{|c|c|c|c|c|}
\hline & \multicolumn{3}{|c|}{ Comorbidity } & \multirow[b]{2}{*}{$\mathrm{p}$} \\
\hline & None, n (\%) & $\begin{array}{c}\text { One or more, } \\
\mathrm{n}(\%)\end{array}$ & $\begin{array}{c}\text { OR } \\
(95 \% \mathrm{CI})\end{array}$ & \\
\hline Bile stone & 187 (66.1) & 96 (33.9) & ref & \\
\hline Alcohol & $43(78.2)$ & 12 (21.8) & $\begin{array}{c}0.54 \\
(0.27-1.08)\end{array}$ & 0.081 \\
\hline Miscellaneous & 28 (59.6) & $19(40.4)$ & $\begin{array}{c}1.32 \\
(0.70-2.49)\end{array}$ & 0.387 \\
\hline Idiopathic & $22(55.0)$ & $18(45.0)$ & $\begin{array}{c}1.59 \\
(0.82-3.11)\end{array}$ & 0.173 \\
\hline ERCP & $12(65.2)$ & $7(36.8)$ & $\begin{array}{c}1.14 \\
(0.43-2.98)\end{array}$ & 0.795 \\
\hline Not assessed & 64 (52.9) & 57 (47.1) & $\begin{array}{c}1.74 \\
(1.13-2.68)\end{array}$ & 0.013 \\
\hline
\end{tabular}

$\mathrm{p}=0.025$ for distribution across comorbidity by Adjusted Binary Logistic Regression (enter model).

Table 4. Age across likely etiology of first episode acute pancreatitis.

\begin{tabular}{cccc}
\hline & N & Mean $(95 \% \mathrm{CI})$ & ANOVA \\
\hline Bile stones & 283 & $59.9(57.5-62.3)$ & \\
Alcohol & 55 & $48.04(44.0-52.1)^{*}$ & \\
Miscellaneous & 47 & $59.7(53.9-65.6)$ & \\
Idiopathic & 40 & $57.0(51.3-62.6)$ & $\mathrm{p}<0.001$ \\
ERCP & 19 & $55.8(45.8-65.8)$ & \\
Not assessed & 121 & $63.2(60.1-66.3)$ \\
\hline
\end{tabular}

p $<0.001$ for alcohol compared to bile stone and not assessed, and $\mathrm{p}=$ 0.026 for alcohol compared to miscellaneous by Tukey HSD contrast.

symptom onset and amongst women, a pre hospital delay of more than 24 hours was associated with a significantly reduced risk of ICU admittance $(p=0.038)$ (Table 5).

Women without a reported aetiology of acute pancreatitis were at a significantly increased risk of ICU treatment (OR 3.53; 95\% CI 1.08 - 11.46, p = 0.036). The miscellaneous group of aetiologies also tended to increase the risk of ICU admittance (OR 3.4, 0.81 - 14.75, $\mathrm{p}=0.094)$. Other causes of pancreatitis were statistically not associated with increased risk of ICU treatment. Women in need of ICU treatment were somewhat older than women treated in wards, and again comorbidity and increasing numbers of diseases tended to increase the risk of admittance to an ICU, but the difference did not reach a statistically significant level (Table 5).

Men with three or more comorbid diseases were at a significantly increased risk of admittance into ICU (OR: 16; 95\% CI 1.38 - 185.4, p = 0.027). Alcohol was the 
Table 5. Patient factors and risk of ICU admittance amongst women during first episode of acute pancreatitis.

\begin{tabular}{|c|c|c|c|c|c|c|c|}
\hline \multirow[b]{3}{*}{ Age per 10 years } & \multicolumn{3}{|c|}{ Descriptive Stats } & \multicolumn{4}{|c|}{ Unadjusted regression } \\
\hline & \multirow[t]{2}{*}{ Uncomplicated n (\%) } & \multirow[t]{2}{*}{ ICU admission n (\%) } & \multirow[t]{2}{*}{ Total n (\%) } & \multirow{2}{*}{$\begin{array}{c}\text { OR } \\
1.221\end{array}$} & \multicolumn{2}{|c|}{$95 \%$ CI } & \multirow{2}{*}{$\begin{array}{c}\mathrm{p} \\
0.129\end{array}$} \\
\hline & & & & & 0.944 & 1.579 & \\
\hline \multicolumn{8}{|l|}{ Comorbidity: } \\
\hline - None & $184(94.8)$ & $10(5.2)$ & $194(64.8)$ & 1 & & & \\
\hline - Coronary & $51(91.1)$ & $5(8.9)$ & 56 (18.7) & 1.88 & 0.63 & 5.59 & 0.252 \\
\hline - Lung & 22 (91.7) & $2(8.3)$ & $24(8.0)$ & 1.57 & 0.33 & 7.33 & 0.562 \\
\hline - DM & 17 (94.4) & $1(5.6)$ & $18(6.0)$ & 0.97 & 0.12 & 7.79 & 0.980 \\
\hline - Liver/kidney & $8(88.9)$ & $1(11.1)$ & $9(3.0)$ & 2.14 & 0.25 & 18.17 & 0.486 \\
\hline - Malignancy & $24(96.0)$ & $1(4.0)$ & $25(8.3)$ & 0.67 & 0.08 & 5.28 & 0.706 \\
\hline No of comorbidities: & & & & & & & 0.507 \\
\hline-0 & $184(94.8)$ & $10(5.2)$ & 194 (64.9) & 1 & & & \\
\hline-1 & 76 (93.8) & $5(6.2)$ & $81(27.1)$ & 1.21 & 0.40 & 3.66 & 0.735 \\
\hline-2 & $19(95.0)$ & $1(5.0)$ & $20(6.7)$ & 0.96 & 0.11 & 7.98 & 0.976 \\
\hline$->3$ & $3(75.0)$ & $1(25.0)$ & $4(1.3)$ & 6.13 & 0.58 & 64.37 & 0.131 \\
\hline \multicolumn{8}{|l|}{ Patient delay: } \\
\hline$-<24 \mathrm{~h}$ & 151 (90.9) & $15(9.1)$ & $166(62.4)$ & 1 & & & \\
\hline$->24 \mathrm{~h}$ & $98(98.0)$ & $2(2.0)$ & $100(37.6)$ & 0.20 & 0.04 & 0.91 & 0.038 \\
\hline Aetiology: & & & & & & & 0.335 \\
\hline - Bile stone & 166 (96.5) & $6(3.5)$ & $172(57.5)$ & 1 & & & \\
\hline - Alcohol & $8(88.9)$ & $1(11.1)$ & $9(3.0)$ & 3.45 & 0.37 & 32.25 & 0.276 \\
\hline - Miscellaneous & $24(40.0)$ & $3(60.0)$ & $27(9.0)$ & 3.45 & 0.81 & 14.75 & 0.094 \\
\hline - Idiopathic & 21 (95.5) & $1(4.5)$ & $22(7.4)$ & 1.31 & 0.15 & 11.48 & 0.803 \\
\hline - ERCP & $16(100)$ & $0(0.0)$ & $16(5.4)$ & 0.00 & 0.00 & . & 0.999 \\
\hline - Not assessed & 47 (88.7) & $6(11.3)$ & 53 (17.7) & 3.53 & 1.08 & 11.46 & 0.036 \\
\hline
\end{tabular}

Many patients with a specified comorbidity had one or more additional comorbid conditions. Percentages shown for Uncomplicated and ICU admission as fractions of total in each row, whereas the percentage of total in each row are presented as fraction of total number of patients.

dominating and only significant aetiological risk factor (36.4\%) for ICU admission amongst men (OR: 4.54; $95 \%$, CI $1.71-12.04, p=0.002)$. Other likely causes of acute pancreatitis were statistically not associated with increased risk for ICU admittance amongst men. Neither co-morbidity nor patients' delay was verified as risk factor for ICU admission amongst men, but a non-statistical trend of a higher prevalence of coronary heart disease and a lower median age was observed amongst men treated in the ICU (Table 6).

\subsection{Adjusted Regression}

When all studied variables were adjusted for in the regression model, likely aetiology of acute pancreatitis remained the most important risk factor for admittance into an ICU ( $p=0.007)$. With bile stone as reference, alcohol implied a fivefold increase in risk for admittance to an ICU (OR: 4.99, 95\%, CI: 2.04 - 12.19, p < 0.001). This association was marked amongst men, (OR: 4.27; $95 \%$, CI 1.51 - 12.03, $\mathrm{p}=0.006$ ) but not seen in women (Table 7). Patients with more than two co-morbidities were confined with an increased risk of ICU admittance (OR: 10.67, 95\%, CI: 1.73 - 65.82, p = 0.011), and again this was verified only amongst men (OR: 25.05, 95\%, CI: 1.84 - 341.77, $\mathrm{p}=0.16$ ).

\section{Discussion}

This study shows that the risk of ICU admittance due to 
Table 6. Patient factors and risk of ICU admittance amongst men during first episode of acute pancreatitis.

\begin{tabular}{|c|c|c|c|c|c|c|c|}
\hline \multirow[b]{3}{*}{ Age per 10 years } & \multicolumn{3}{|c|}{ Descriptive Stats } & \multicolumn{4}{|c|}{ Unadjusted regression } \\
\hline & \multirow[t]{2}{*}{ Uncomplicated n (\%) } & \multirow[t]{2}{*}{ ICU admission n (\%) } & \multirow[t]{2}{*}{ Total n (\%) } & \multirow{2}{*}{$\begin{array}{c}\text { OR } \\
0.901\end{array}$} & \multicolumn{2}{|c|}{$95 \%$ CI } & \multirow{2}{*}{$\begin{array}{c}\mathrm{p} \\
0.328\end{array}$} \\
\hline & & & & & 0.731 & 1.110 & \\
\hline \multicolumn{8}{|l|}{ Co morbidity: } \\
\hline - None & 144 (88.9) & $18(11.1)$ & $162(60.9)$ & 1 & & & \\
\hline - Coronary & $40(81.6)$ & $9(18.4)$ & $49(18.4)$ & 1.80 & 0.78 & 4.18 & 0.166 \\
\hline - Lung & $27(84.4)$ & $5(15.6)$ & $32(12.0)$ & 1.36 & 0.48 & 3.82 & 0.557 \\
\hline - DM & 13 (76.5) & $4(23.5)$ & $17(6.3)$ & 2.33 & 0.71 & 7.64 & 0.161 \\
\hline - Liver/kidney & $9(81.8)$ & $2(18.2)$ & $11(4.1)$ & 1.60 & 0.33 & 7.77 & 0.556 \\
\hline - Malignancy & $17(85.0)$ & $3(15.0)$ & $20(7.5)$ & 1.27 & 0.35 & 4.59 & 0.715 \\
\hline \multicolumn{8}{|c|}{ No of comorbidities: } \\
\hline-0 & 144 (88.9) & $18(11.1)$ & $162(60.9)$ & 1 & & & 0.156 \\
\hline-1 & 73 (87.9) & $10(12.1)$ & $83(31.2)$ & 1.09 & 0.48 & 2.49 & 0.827 \\
\hline-2 & $15(83.3)$ & $3(16.7)$ & $18(6.8)$ & 1.60 & 0.42 & 6.06 & 0.489 \\
\hline$->3$ & $1(33.3)$ & $2(66.7)$ & $3(1.1)$ & 16.00 & 1.38 & 185.40 & 0.027 \\
\hline \multicolumn{8}{|l|}{ Patient delay: } \\
\hline$-<24 \mathrm{~h}$ & $116(86.6)$ & $18(13.4)$ & $134(55.1)$ & 1 & & & \\
\hline$->24 \mathrm{~h}$ & $95(87.2)$ & $14(12.8)$ & 109 (44.9) & 0.95 & 0.44 & 2.00 & 0.893 \\
\hline Aetiology: & & & & & & & 0.071 \\
\hline - Bile stone & 103 (92.8) & $8(7.2)$ & $111(41.7)$ & 1 & & & \\
\hline - Alcohol & 34 (73.9) & $12(26.1)$ & 46 (17.3) & 4.54 & 1.71 & 12.04 & 0.002 \\
\hline - Miscellaneous & $17(85.0)$ & $3(15.0)$ & $20(7.5)$ & 2.27 & 0.54 & 9.42 & 0.258 \\
\hline - Idiopathic & $18(100)$ & - & $18(6.8)$ & & & & \\
\hline - ERCP & $2(66.7)$ & $1(33.3)$ & $3(1.1)$ & 6.43 & 0.52 & 78.89 & 0.145 \\
\hline - Not assessed & $59(86.8)$ & $9(13.2)$ & $68(25.6)$ & 1.96 & 0.71 & 5.364 & 0.180 \\
\hline
\end{tabular}

Many patients with a specified comorbidity had one or more additional comorbid conditions. Percentages shown for Uncomplicated and ICU admission as fractions of total in each row, whereas the percentages of total in each row are presented as fraction of total number of patients.

first episode of acute pancreatitis is predominantly determined by the aetiology of acute pancreatitis and especially regular consumption of alcohol (Tables 2 and 6). Alcohol associated acute pancreatitis is dominated by younger men, and men are more at risk than women for ICU admittance during their first episode acute pancreatitis. Moreover, men are less likely to have adequate assessment of aetiology of acute pancreatitis. Bile stone disease is the overall dominating cause of first episode acute pancreatitis, and women are more at risk than men for ERCP and bile stone associated acute pancreatitis but bile stone disease is not a very frequent cause of ICU admittance. Whereas the risk of ICU admittance amongst women is reduced when the delay exceed 24 hours, an increasing pre hospital delay increases the risk of ICU admittance amongst patients with alcohol associated pancreatitis. Patients with more than 2 accompanying diseases are also at increased risk of ICU treatment.

ICU admittance is the worst case scenario for patients with severe acute pancreatitis but the mortality rate amongst ICU patients in this study (24\%) is well within the range of reported morbidity and mortality rates (21.0\% - 53.6\%) [5,24-26]. 9\% of patients in this cohort are admitted for ICU treatment, which correlates well with a recent study by Shen et al where $10.3 \%$ of all patients admitted with their first episode of acute pancreatitis received treatment in an intensive care unit [27]. Other studies show higher ICU admittance rates [28,29].

The mortality rates and ICU admissions are consistent with other studies and ICU admission a representative 
Table 7. Adjusted analyses of patient factors and risk of ICU admittance during first episode of acute pancreatitis.

\begin{tabular}{|c|c|c|c|c|c|c|c|c|c|c|c|c|}
\hline \multirow{3}{*}{ Gender: } & \multicolumn{4}{|c|}{ Adjusted regression } & \multicolumn{4}{|c|}{ Adjusted regression, women only } & \multicolumn{4}{|c|}{ Adjusted regression, men only } \\
\hline & \multirow[t]{2}{*}{ OR } & \multicolumn{2}{|c|}{$95 \%$ CI } & \multirow[t]{2}{*}{$\mathrm{p}$} & \multirow[t]{2}{*}{ OR } & \multicolumn{2}{|c|}{$95 \%$ CI } & \multirow[t]{2}{*}{$\mathrm{p}$} & \multirow[t]{2}{*}{ OR } & \multicolumn{2}{|c|}{$95 \%$ CI } & \multirow[t]{2}{*}{$\mathrm{p}$} \\
\hline & & & & & & & & & & & & \\
\hline - Female & & & & & & & & & & & & \\
\hline - Male & 1.704 & 0.872 & 3.333 & 0.119 & & & & & & & & \\
\hline Age & 1.000 & 0.981 & 1.019 & 0.972 & 1.013 & 0.982 & 1.045 & 0.413 & 0.985 & 0.959 & 1.012 & 0.275 \\
\hline \multicolumn{13}{|l|}{ Co morbidity: } \\
\hline - None & & & & 0.087 & & & & 0.562 & & & & 0.088 \\
\hline-1 & 1.169 & 0.560 & 2.440 & 0.677 & 0.811 & 0.239 & 2.749 & 0.737 & 1.521 & 0.576 & 4.018 & 0.397 \\
\hline-2 & 1.451 & 0.428 & 4.918 & 0.550 & 0.730 & 0.079 & 6.720 & 0.781 & 2.609 & 0.568 & 11.977 & 0.218 \\
\hline - 3 or more & 10.665 & 1.728 & 65.819 & 0.011 & 6.819 & 0.342 & 136.117 & 0.209 & 25.052 & 1.836 & 341.771 & 0.016 \\
\hline \multicolumn{13}{|l|}{ Patient delay: } \\
\hline \multicolumn{13}{|l|}{$-<24 \mathrm{~h}$} \\
\hline$->24 \mathrm{~h}$ & 0.600 & 0.308 & 1.167 & 0.132 & 0.215 & 0.043 & 1.071 & 0.061 & 0.908 & 0.403 & 2.045 & 0.816 \\
\hline \multicolumn{13}{|l|}{ Aetiology: } \\
\hline - Bile stone & & & & 0.010 & & & & 0.610 & & & & 0.094 \\
\hline - Alcohol & 4.989 & 2.042 & 12.187 & 0.000 & 3.469 & 0.329 & 36.591 & 0.301 & 4.265 & 1.512 & 12.028 & 0.006 \\
\hline - Miscellaneous & 1.945 & 0.611 & 6.197 & 0.260 & 2.577 & 0.520 & 12.767 & 0.246 & 1.059 & 0.163 & 6.887 & 0.952 \\
\hline - Idiopathic & 0.385 & 0.048 & 3.056 & 0.366 & 1.022 & 0.114 & 9.210 & 0.984 & 0.000 & 0.000 & & 0.998 \\
\hline - ERCP & 1.251 & 0.150 & 10.394 & 0.836 & 0.000 & 0.000 & & 0.999 & 5.105 & 0.394 & 66.164 & 0.212 \\
\hline - Not assessed & 1.981 & 0.892 & 4.397 & 0.093 & 2.714 & 0.808 & 9.114 & 0.106 & 1.389 & 0.481 & 4.013 & 0.544 \\
\hline
\end{tabular}

Adjusted binary logistic regression (enter model).

and valid outcome parameter. The case fatality rate of first episode acute pancreastitis increases with the number of concomitant conditions [24]. Frey et al. [24] also show that over $60 \%$ of pancreatitis cases have one or more co-morbid conditions, approaching 95\% amongst patients with alcohol associated pancreatitis and $40 \%$ of these patients have three or more conditions.

The prevalence of concomitant conditions is less in our cohort of patients (Table 2) and alcohol associated acute pancreatitis occur amongst the youngest patients (Table 4), which tend to have the fewest concomitant conditions (Table 3). Moreover, the association between comorbidity and precipitation of multiple organ failure is less clear and no single comorbid condition is associated with ICU admittance (Table 2). An increasing risk of ICU admittance with increasing number of concomitant conditions is noticed (Table 2 and $\mathbf{6}$ ), but few patients have three or more concomitant conditions and the risk is associated with male gender (Table 7). Thus, comorbidity may contribute to progression of acute pancreatitis towards organ dysfunction and ICU admittance, but more likely, comorbid conditions increase the risk of death once a clinical situation with fully developed septicaemia and multiple organ failure is developed [30].

Similar reasoning may explain the missing effect of age on ICU admittance in this study. Increasing age is recognised as a risk for overall death [25] and death in severe acute pancreatitis [26] and aging implies accumulation of an increasing number of comorbid conditions [25], whereas age not necessarily increase the risk of acute pancreatitis progressing towards multiple organ failure.

There is a balanced distribution of acute pancreatitis across gender in this series of patients, which is in concordance with gender specific incidence rates in Scandinavia for this period of time [31].

The association between gender and ICU admittance or severe pancreatitis is not readily identified in all studies [21], and when analyses are adjusted for all risk factors for ICU admittance, the association with gender is 
eliminated, leaving aetiology and specifically alcohol associated pancreatitis with a fivefold risk for ICU admittance during first episode of acute pancreatitis (Table 6). The association is, nevertheless, only statistically verified amongst male patients (Table 6). Alcohol consumption is the dominating cause of severe acute pancreatitis and ICU admittance (44.4\% - 79.3\%) in several countries, and alcohol especially dominates as cause of severe acute pancreatitis amongst men (85.5\%) over women $(45.5 \%)$ in Finland $[5,19,26]$. These results support Lankish, et al. [32] findings of alcohol associated acute pancreatitis as risk factor for artificial ventilation. However, the effect of alcohol on progression of alcohol associated pancreatitis towards ICU admittance is not easily explained. Patients with alcohol associated acute pancreatitis traditionally present one or more comorbid condition (95\%) and $40 \%$ of these cases have three or more comorbid conditions, which are very strong predictors of early death among patients with acute pancreatitis [24]. Although comorbidity is associated with increased risk of death in earlier reports, the prevalence of comorbid condition amongst alcohol associated AP in this study is much lower than that reported by Frey, et al. (Table 3) and comorbidity is not a statistical risk of progression towards ICU admittance in this study. This study suggests that comorbidity may be a confounder in progression of acute pancreatitis and a risk factor for death only when multiple organ failure is fully developed.

Cases with non-assessed aetiology of acute pancreatitis is associated with increased risk of ICU admittance (Table 2) and male gender (Table 1), although only a trend was identified in adjusted analyses. This group of patients is most likely very heterogeneous. The gender profile and risk profile for ICU admittance amongst these patients is very similar to that of alcohol associated pancreatitis (Table 1), and the fraction of alcohol associated pancreatitis in this series of patients is somewhat lower than in comparable communities $[5,19,26]$. Regular alcohol consumption and especially addiction to alcohol is still not socially accepted in this community and denial of alcohol consumption may be disguised in this nonassessed group of patients. The stigma of an alcohol related disease is even higher amongst women in Norway, and women with non-assessed aetiology of acute pancreatitis are here statistically at risk of ICU admittance (Table 4). A less than satisfactory diagnostic follow up due to lack of compliance amongst men after an episode of acute pancreatitis may also contribute to the group of non-assessed patients [25].

Bile stone disease, although the most frequent cause of first episode acute pancreatitis, is associated with one of the lowest risks of ICU admittance in this series of patients, which is consistent with several other reports [10, $27,33]$. Bile stone disease serves as reference in the analyses.

Huang, et al. show that the rates of bile stone related ERCP procedures are roughly similar across gender [34], but this as well as other studies show that women are more at risk of ERCP associated acute pancreatitis (Table 2) $[33,35,36]$. Intervention towards bile stone disease reduce the risk of a second episode of acute pancreatitis, but it is a paradox that treatment strategy may imply further risk for patients and that less resources are devoted to causes of first episode of acute pancreatitis with higher risk of ICU admittance and recurrence.

Treatment delay implies increasing risk of death from perforated ulcer disease and intestinal obstruction and is probably associated with progression of disease and complication over time [37,38]. A similar risk of organ dysfunction and ICU admittance during first episode of acute pancreatitis is only confirmed in sub analyses amongst patients with alcohol associated pancreatitis. The inverse and reduced risk of ICU admittance amongst females with pre hospital delay exceeding 24 hours (Table 5) is not easily explained, but the different effect of delay may be related to likely etiology of acute pancreatitis and the reduced risk of ICU admittance with time amongst women may balance the increased risk with time amongst alcohol associated pancreatitis dominated by males and therefore disguise any effect of delay in overall analyses (Table 2).

The retrospective design in this study is sought compensated for by structured registration and focus on few objective variables and a conservative attitude towards the dataset. Studies on severe acute pancreatitis often involve any episodes of a consecutive number of pancreatitis in individuals admitted for treatment of acute pancreatitis [39], whereas this study only includes patients with first episode acute pancreatitis, which together with the second episode, are the most severe episodes of acute pancreatitis [40]. Moreover, by limiting recruitment of patient to a well-defined urban area; this study gives unique and robust analyses of ICU admittance risks due to first episode acute pancreatitis. The $66 \%$ accuracy of acute pancreatitis registered in PIMS is consistent with the report of Nøjgaard, et al. [41] that show incidence rates of $51 \%-73 \%$ of incidence rates in official health registries when international diagnostic criteria of acute pancreatitis are followed.

\section{Conclusion}

Multi organ failure and ICU admittance is associated with the highest mortality in acute pancreatitis. Regular alcohol consumption, male gender, and delayed hospital admittance are factors associated with an increased risk of ICU admittance during first episode acute pancreatitis. This group of patients should probably be noticed at hospital admittance and offered reinforced treatment and 
care in order to reduce the risk of organ failure and admittance to intensive care units.

\section{REFERENCES}

[1] D. N. Schmidt, “Apparent Risk Factors for Chronic and Acute Pancreatitis in Stockholm County. Spirits but Not Wine and Beer,” International Journal of Pancreatology, Vol. 8, No. 1, 1991, pp. 45-50.

[2] P. A. Banks, "Epidemiology, Natural History, and Predictors of Disease Outcome in Acute and Chronic Pancreatitis,” Gastrointestinal Endoscopy, Vol. 56, No. 6, 2002, pp. 226-230. doi:10.1016/S0016-5107(02)70016-3

[3] T. Omdal, J. Dale, S. A. Lie, K. B. Iversen, H. Flaaten and K. K. Ovrebo, ”Time Trends in Incidence, Etiology, and Case fatality Rate of the First Attack of Acute Pancreatitis," Scandinavian Journal of Gastroenterology, Vol. 46, No. 11, 2011, pp. 1389-1398. doi:10.3109/00365521.2011.605464

[4] H. Gislason, A. Horn, D. Hoem, A. Andren-Sandberg, A. K. Imsland, O. Soreide, et al., "Acute Pancreatitis in Bergen, Norway. A Study on Incidence, Etiology and Severity,” Scandinavian Journal of Gastroenterology, Vol. 93, No. 1, 2004, pp. 29-33.

[5] H. E. Lilja, A. Leppaniemi and E. Kemppainen, "Utilization of Intensive Care Unit Resources in Severe Acute Pancreatitis,” Journal of the Pancreas, Vol. 9, No. 2, 2008, pp. 179-184.

[6] J. Mayerle, V. Hlouschek and M. M. Lerch, "Current Management of Acute Pancreatitis,” Nature Clinical Practice Gastroenterology \& Hepatology, Vol. 2, No. 10, 2005, pp. 473-483. doi:10.1038/ncpgasthep0293

[7] H. G. Beger and B. M. Rau, "Severe Acute Pancreatitis: Clinical Course and Management,” World Journal of Gastroenterology, Vol. 13, No. 38, 2007, pp. 5043-5051.

[8] S. R. Eachempati, L. J. Hydo and P. S. Barie, "Severity Scoring for Prognostication in Patients with Severe Acute Pancreatitis: Comparative Analysis of the Ranson Score and the APACHE III Score,” Archives of Surgery, Vol. 137, No. 6, 2002, pp. 730-736. doi:10.1001/archsurg.137.6.730

[9] M. Williams and H. H. Simms, "Prognostic Usefulness of Scoring Systems in Critically Ill Patients with Severe Acute Pancreatitis," Critical Care Medicine, Vol. 27, No. 5, 1999, pp. 901-907. doi:10.1097/00003246-199905000-00023

[10] P. W. Vriens, P. van de Linde, E. T. Slotema, P. E. Warmerdam and P. J. Breslau, "Computed Tomography Severity Index Is an Early Prognostic Tool for Acute Pancreatitis," Journal of the American College of Surgeons, Vol. 201, No. 4, 2005, pp. 497-502. doi:10.1016/j.jamcollsurg.2005.06.269

[11] D. Juneja, P. B. Gopal and M. Ravula, "Scoring Systems in Acute Pancreatitis: Which One to Use in Intensive Care Units,” Journal of Critical Care, Vol. 25, No. 2, 2010, pp. e9-e15.

[12] E. Gocmen, Y. A. Klc, O. Yoldas, T. Ertan, N. Karakose, M. Koc, et al., "Comparison and Validation of Scoring
Systems in a Cohort of Patients Treated for Biliary Acute Pancreatitis,” Pancreas, Vol. 34, No. 1, 2007, pp. 66-69. doi:10.1097/01.mpa.0000246667.53622.e3

[13] T. K. Leung, C. M. Lee, S. Y. Lin, H. C. Chen, H. J. Wang, L. K. Shen, et al., "Balthazar Computed Tomography Severity Index Is Superior to Ranson Criteria and APACHE II Scoring System in Predicting Acute Pancreatitis Outcome," World Journal of Gastroenterology, Vol. 11, No. 38, 2005, pp. 6049-6052.

[14] T. E. Pavlidis, E. T. Pavlidis and A. K. Sakantamis, “Advances in Prognostic Factors in Acute Pancreatitis: A Mini-Review," Hepatobiliary \& Pancreatic Diseases International, Vol. 9, No. 5, 2010, pp. 482-486.

[15] G. Gravante, G. Garcea, S. L. Ong, M. S. Metcalfe, D. P. Berry, D. M. Lloyd, et al., "Prediction of Mortality in Acute Pancreatitis: A Systematic Review of the Published Evidence,” Pancreatology, Vol. 9, No. 5, 2009, pp. 601614. doi:10.1159/000212097

[16] M. Abu-Hilal and T. Armstrong, "The Impact of Obesity on the Course and Outcome of Acute Pancreatitis," Obesity Surgery, Vol. 18, No. 3, 2008, pp. 326-328. doi:10.1007/s11695-007-9298-5

[17] L. Company, J. Saez, J. Martinez, J. R. Aparicio, R. Laveda, P. Grino, et al., "Factors Predicting Mortality in Severe Acute Pancreatitis,” Pancreatology, Vol. 3, No. 2, 2003, pp. 144-148. doi:10.1159/000070083

[18] D. Yadav and D. C. Whitcomb, "The Role of Alcohol and Smoking in Pancreatitis,” Nature Reviews Gastroenterology \& Hepatology, Vol. 7, No. 3, 2010, pp. 131-145. doi:10.1038/nrgastro.2010.6

[19] J. D. Wig, K. G. Bharathy, R. Kochhar, T. D. Yadav, A. K. Kudari, R. P. Doley, et al., "Correlates of Organ Failure in Severe Acute Pancreatitis,” Journal of the Pancreas, Vol. 10, No. 3, 2009, pp. 271-275.

[20] J. L. Mee, F. Paye, A. Sauvanet, D. O’Toole, P. Hammel, J. Marty, et al., "Incidence and Reversibility of Organ Failure in the Course of Sterile or Infected Necrotizing Pancreatitis,” Archives of Surgery, Vol. 136, No. 12, 2009, pp. 1386-1390. doi:10.1001/archsurg.136.12.1386

[21] A. Buter, C. W. Imrie, C. R. Carter, S. Evans and C. J. McKay, "Dynamic Nature of Early Organ Dysfunction Determines Outcome in Acute Pancreatitis,” British Journal of Surgery, Vol. 89, No. 3, 2002, pp. 298-302. doi:10.1046/j.0007-1323.2001.02025.x

[22] D. Radenkovic, D. Bajec, N. Ivancevic, N. Milic, V. Bumbasirevic, V. Jeremic, et al., "D-Dimer in Acute Pancreatitis: A New Approach for an Early Assessment of Organ Failure. Pancreas, Vol. 38, No. 6, 2009, pp. 655-660. doi:10.1097/MPA.0b013e3181a66860

[23] E. L. Bradley, "A Clinically Based Classification System for Acute Pancreatitis. Summary of the International Symposium on Acute Pancreatitis, Atlanta, Ga, September 11-13, 1992,” Archives of Surgery, Vol. 128, No. 5, 1993, pp. 586-590. doi:10.1001/archsurg.1993.01420170122019

[24] C. Frey, H. Zhou, D. Harvey and R. H. White, “Co-Morbidity Is a Strong Predictor of Early Death and MultiOrgan System Failure among Patients with Acute Pancreatitis,” Journal of Gastrointestinal Surgery, Vol. 11, 
No. 6, 2007, pp. 733-742. doi:10.1007/s11605-007-0164-5

[25] N. Ahmadi, D. Shavelle, V. Nabavi, F. Hajsadeghi, S. Moshrefi, F. Flores, et al., "Coronary Distensibility Index Measured by Computed Tomography Is Associated with the Severity of Coronary Artery Disease," Journal of Cardiovascular Computed Tomography, Vol. 4, No. 2, 2010, pp. 119-126. doi:10.1016/j.jcct.2010.01.007

[26] K. I. Halonen, A. K. Leppaniemi, P. A. Puolakkainen, J. E. Lundin, E. A. Kemppainen, A. J. Hietaranta, et al., "Severe Acute Pancreatitis: Prognostic Factors in 270 Consecutive Patients,” Pancreas, Vol. 21, No. 3, 2000, pp. 266271. doi:10.1097/00006676-200010000-00008

[27] H. N. Shen and C. L. Lu, "Incidence, Resource Use, and Outcome of Acute Pancreatitis with/without Intensive Care: A Nationwide Population-Based Study in Taiwan,” Pancreas, Vol. 40, No. 1, 2011, pp. 10-15. doi:10.1097/MPA.0b013e3181f7e750

[28] T. Bruennler, O. W. Hamer, S. Lang, S. Gruene, C. E. Wrede, N. Zorger, et al., "Outcome in a Large Unselected Series of Patients with Acute Pancreatitis," Hepatogastroenterology, Vol. 56, No. 91-92, 2009, pp. 871-876.

[29] J. P. Neoptolemos, M. Raraty, M. Finch and R. Sutton, "Acute Pancreatitis: The Substantial Human and Financial Costs,” Gut, Vol. 42, No. 6, 1998, pp. 886-891. doi:10.1136/gut.42.6.886.

[30] T. A. Williams, G. J. Dobb, J. C. Finn, M. W. Knuiman, E Geelhoed, K. Y. Lee, et al., "Determinants of LongTerm Survival after Intensive Care," Critical Care Medicine, Vol. 36, No. 5, 2008, pp. 1523-1530. doi:10.1097/CCM.0b013e318170a405

[31] B. Sandzen, M. Rosenmuller, M. M. Haapamaki, E. Nilsson, H. C. Stenlund and M. Oman, "First Attack of Acute Pancreatitis in Sweden 1988-2003: Incidence, Aetiological Classification, Procedures and Mortality-A Register Study,” BMC Gastroenterology, Vol. 9, No. 5, 2009, p. 18. doi:10.1186/1471-230X-9-18

[32] P. G. Lankisch, C. Assmus, D. Pflichthofer, K. Struckmann and D. Lehnick, "Which Etiology Causes the Most Severe Acute Pancreatitis," International Journal of Pancreatology, Vol. 26, No. 2, 1999, pp. 55-57.

\section{doi:10.1007/BF02781731}

[33] J. van der Voort, R. M. Soetikno, T. C. Tham, R. C. Wong, A. P. Ferrari, H. Montes, et al., "Risk Factors for Complications after Performance of ERCP,” Gastrointestinal Endoscopy, Vol. 56, No. 5, 2002, pp. 652-656. doi:10.1016/S0016-5107(02)70112-0

[34] J. Huang, C. H. Chang, J. L. Wang, H. K. Kuo, J. W. Lin, W. Y. Shau, et al., "Nationwide Epidemiological Study of Severe Gallstone Disease in Taiwan,” BMC Gastroenterology, Vol. 9, No. 22, 2009, p. 63. doi:10.1186/1471-230X-9-63

[35] G. J. Wang, C. F. Gao, D. Wei, C. Wang and S. Q. Ding, "Acute Pancreatitis: Etiology and Common Pathogenesis," World Journal of Gastroenterology, Vol. 15, No. 12, 2009, pp. 1427-1430. doi:10.3748/wjg.15.1427

[36] M. L. Freeman, J. A. DiSario, D. B. Nelson, M. B. Fennerty, J. G. Lee, D. J. Bjorkman, et al., "Risk Factors for PostERCP Pancreatitis: A Prospective, Multicenter Study," Gastrointestinal Endoscopy, Vol. 54, No. 4, 2001, pp. 425434. doi:10.1067/mge.2001.117550

[37] B. T. Fevang, J. M. Fevang, O. Soreide, K. Svanes and A. Viste, "Delay in Operative Treatment among Patients with Small Bowel Obstruction," Scandinavian Journal of Surgery, Vol. 92, No. 2, 2003, pp. 131-137.

[38] C. Svanes, R. T. Lie, K. Svanes, S. A. Lie and O. Soreide, "Adverse Effects of Delayed Treatment for Perforated Peptic Ulcer,” Annals of Surgery, Vol. 220, No. 2, 1994, pp. 168-175. doi:10.1097/00000658-199408000-00008

[39] I. Glambek, G. Kvaale, B. Arnesjo and O. Soreide, "Prevalence of Gallstones in a Norwegian Population," Scandinavian Journal of Gastroenterology, Vol. 22, No. 9, 1987, pp. 1089-1094. doi:10.3109/00365528708991963

[40] R. Andersson, B. Andersson, P. Haraldsen, G. Drewsen and G. Eckerwall, "Incidence, Management and Recurrence Rate of Acute Pancreatitis," Scandinavian Journal of Gastroenterology, Vol. 39, No. 9, 2004, pp. 891-894. doi:10.1080/00365520410007061

[41] C. Nojgaard, F. Bendtsen, P. Matzen and U. Becker, "The Aetiology of Acute and Chronic Pancreatitis over Time in a Hospital in Copenhagen,” Danish Medical Bulletin, Vol. 57, No. 1, 2010, p. A4103. 